\title{
Antiphospholipid antibodies in Brazilian hepatitis $C$ virus carriers
}

\author{
A.M. Atta ${ }^{1}$, P. Estevam², R. Paraná3 ${ }^{3}$ C.M. Pereira ${ }^{1}$, B.C.O. Leite ${ }^{1}$ \\ and M.L.B. Sousa-Atta ${ }^{1}$
}

${ }^{1}$ Departamento de Análises Clínicas e Toxicológicas, Faculdade de Farmácia, ${ }^{2}$ Programa de Pós-Graduação em Imunologia, Instituto de Ciências da Saúde, ${ }^{3}$ Serviço de Gastroenterologia, Hospital Universitário Professor Edgard Santos, Universidade Federal da Bahia, Salvador, BA, Brasil

Correspondence to: A.M. Atta, Departamento de Análises Clínicas e Toxicológicas, Faculdade de Farmácia, Universidade Federal da Bahia, Rua Barão de Geremoabo, s/nº, Campus UFBA de Ondina, 40170115 Salvador, BA, Brasil

Fax: +55-71-3283-6900. E-mail: ajatta@ig.com.br

Hepatitis C, a worldwide viral infection, is an important health problem in Brazil. The virus causes chronic infection, provoking B lymphocyte dysfunction, as represented by cryoglobulinemia, non-organ-specific autoantibody production, and non-Hodgkin's lymphoma. The aim of this research was to screen for the presence of antiphospholipid autoantibodies in 109 Brazilian hepatitis $\mathrm{C}$ virus carriers without clinical history of antiphospholipid syndrome. Forty healthy individuals were used as the control group. IgA, IgG, and IgM antibodies against cardiolipin and ß2-glycoprotein I were measured with an enzyme-linked immunosorbent assay, using a cut-off point of either $20 \mathrm{UPL}$ or $20 \mathrm{SBU}$. While $24(22.0 \%)$ hepatitis C carriers had moderate titers of IgM anticardiolipin antibodies (median, $22.5 \mathrm{MPL}$; 95\% $\mathrm{Cl}$ : 21.5-25.4 MPL), only three carriers (<3\%) had IgG anticardiolipin antibodies (median, $23 \mathrm{GPL}$; 95\% Cl: 20.5-25.5 GPL). Furthermore, IgA anticardiolipin antibodies were not detected in these individuals. Male gender and IgM anticardiolipin seropositivity were associated in the hepatitis $\mathrm{C}$ group $(P=0.0004)$. IgA antiß2-glycoprotein-I antibodies were detected in 29 of 109 (27.0\%) hepatitis C carriers (median, 41 SAU; 95\%Cl: 52.7-103.9 SAU). Twenty patients (18.0\%) had IgM anti-ß2-glycoprotein I antibodies (median, $27.6 \mathrm{SMU}$; 95\%Cl: 23.3-70.3 SMU), while two patients had IgG antibodies against this protein (titers, 33 and 78 SGU). Antiphospholipid antibodies were detected in only one healthy individual, who was seropositive for IgM anticardiolipin. We concluded that Brazilian individuals chronically infected with hepatitis $C$ virus present a significant production of antiphospholipid antibodies, mainly IgA anti-ß2-glycoprotein I antibodies, which are not associated with clinical manifestations of antiphospholipid syndrome.

Key words: Hepatitis C virus; Antiphospholipid antibody; Brazilian patients

Research supported by DECIT/MS/CNPq (\#403056/2004-7) and FAPESB/MS (\#PS15/2005). P. Estevam was the recipient of a fellowship from CAPES and B.C.O. Leite and C.M. Pereira received fellowships from CNPq (PIBIC). A.M. Atta has a CNPq fellowship for Research Productivity.

Received September 6, 2007. Accepted May 26, 2008

Hepatitis $\mathrm{C}$ is a viral infection transmitted parentally by the hepatitis $\mathrm{C}$ virus ( $\mathrm{HCV}$ ), an enveloped positive stranded RNA Hepacivirus of the Flaviviridae family. The virus has six major genotypes that infect human cells, including hepatocytes, B lymphocytes, dendritic cells, monocytes, and epithelial cells $(1,2)$. It is estimated that about 170 million people in the world, including $1.5-2.0 \%$ of the Brazilian population, are infected with this virus (3).

Features of HCV infection include: i) persistence of the virus, which may cause cirrhosis and hepatocellular carcinoma and ii) autoimmunity, which is mainly represented by cryoglobulinemia and production of non-organ-specific autoantibodies, including antiphospholipid autoantibodies (4-8). Antiphospholipid antibodies are a heterogeneous group of immunoglobulins that react with epitopes of proteins complexed with anionic phospholipids or epitopes of anionic phospholipids. Pathogenic antiphospholipid antibodies are immunoglobulins that react with proteins of the 
coagulation system such as ß2-glycoprotein I (ß2GPI) or prothrombin, causing a coagulation disorder known as antiphospholipid syndrome. Conversely, antiphospholipid antibodies presenting restricted antigen specificity for phospholipid epitopes are commonly found in infectious diseases, such as syphilis, and are not involved with coagulation disorders. Antiphospholipid syndrome may be either a primary disorder or secondarily associated with an autoimmune disease, such as systemic lupus erythematosus. The main features of antiphospholipid syndrome are either venous or arterial thrombosis and recurrent fetal loss (9).

Although antiphospholipid antibodies have been reported in HCV carriers, there have been some contradictory reports about their antigen specificity, isotype seroprevalence, and clinical importance (10). Apparently, environmental factors and the use of non-standardized immunoassays to detect antiphospholipid antibodies have contributed to the inconsistencies observed in different population studies that have investigated antiphospholipid antibodies in hepatitis $\mathrm{C}$ carriers.

In the present research, we investigated the seroprevalence of anticardiolipin and anti-ß2GPI antibodies in HCV carriers from two hepatitis centers in Salvador, BA, Brazil. This investigation was undertaken using the standardized immunoassay kits that are used in most autoimmunity reference laboratories in the world.

One hundred and nine untreated HCV carriers (61 males: median age: 48.0 years, range: $13-86$ years, $95 \% \mathrm{Cl}$ : 45.6-50.9 years; 48 females: median age: 48 years, range: 20-73 years, $95 \% \mathrm{Cl}$ : 44.6-60.0 years) were evaluated. All individuals were classified as HCV carriers after a clinical and laboratory diagnosis of hepatitis $\mathrm{C}$ was established, which included anti-HCV antibody detection by an enzyme-linked immunosorbent assay (ELISA) using structural and non-structural HCV antigens (AXSYM System; Abbott Laboratories, Chicago, IL, USA) and HCV RNA detection by a polymerase chain reaction assay (Amplicor ${ }^{\circledR}$ HCV Detection KIT V2.0; Roche Molecular Systems Inc., Somerville, NJ, USA). In 76 genotyped individuals, genotype 1 was predominant $(\mathrm{N}=49)$, followed by genotype 3 $(\mathrm{N}=23)$, and genotype $2(\mathrm{~N}=4)$. The median level of alanine aminotransferase in the $\mathrm{HCV}$ carrier group was $28.0 \mathrm{U} / \mathrm{L}$ (95\% Cl: $32.8-45.4 \mathrm{U} / \mathrm{L})$, whereas in the healthy individuals it was $8.0 \mathrm{U} / \mathrm{L}$ (range $4-37 \mathrm{U} / \mathrm{L} ; 95 \% \mathrm{Cl}=9.7-$ $15.3 \mathrm{U} / \mathrm{L}$ ). Histologic evaluation of liver biopsies was performed in only 62 cases, using hematoxylin-eosin, Picrosirius red, and Perl's stains (11).

Progressive fibrosis was observed in approximately $40 \%$ of the HCV carriers, which was associated with an evolution of cirrhosis in some of these individuals. Some degree of steatosis was observed in 26 patients, but liver histology showed a portal disease, with portal fibrosis, compatible with chronic viral hepatitis. As recommended by international guidelines, liver biopsy was not performed in patients carrying genotypes 2 and 3 , who should be treated without this exam (11). In contrast, liver biopsy is recommended for genotype 1 patients to determine treatment (11).

Forty healthy blood donors (22 males and 18 females, median age: 32 years, range: $18-61$ years, $95 \% \mathrm{Cl}$ : $30.8-$ 38.5 years) comprised the healthy control group. Informed written consent was obtained from all individuals, and the study was approved by the local Ethics Committee in Human Research (Fiocruz Foundation, Centro de Pesquisa Gonçalo Moniz, BA, Brazil).

Anticardiolipin and anti-ß2GPI antibodies were measured by ELISA (Quanta Lite ${ }^{\mathrm{TM}}$ Microwell ELISA; INOVA Diagnostics, Inc., San Diego, CA, USA). IgA, IgG, and IgM anticardiolipin antibodies were determined with Quanta Lite $^{\text {TM }}$ ACA IgA, IgG, and IgM kits, respectively. Briefly, polystyrene micro-well ELISA plates coated with a purified cardiolipin antigen, as well as both bovine and human ß2GPI, were incubated with $100 \mu \mathrm{L}$ of a 1:101 dilution of the patient's serum sample for $30 \mathrm{~min}$ at $18-22^{\circ} \mathrm{C}$. The micro-well plates were washed three times with phosphate-buffered saline, then incubated with $100 \mu \mathrm{L}$ goat anti-human $\lg \mathrm{A}$, IgG, or IgM peroxidase conjugate under the same conditions. After additional washes, the plates were incubated with $100 \mu \mathrm{L}$ hydrogen peroxide plus tetramethylbenzidine in the dark for $30 \mathrm{~min}$ at $18-22^{\circ} \mathrm{C}$. The enzymatic reactions were stopped with $0.344 \mathrm{M}$ sulfuric acid and their absorbances at 450 and $620 \mathrm{~nm}$ were measured using an ELISA reader. The anticardiolipin antibody titer of each serum sample was calculated using a reference curve consisting of five standards of known concentrations of $\lg \mathrm{A}$, $\lg \mathrm{G}$, or $\lg \mathrm{M}$ anticardiolipin antibodies. The anticardiolipin antibody titer was reported as standard IgA anticardiolipin units (APL), standard IgG anticardiolipin units (GPL), or standard IgM anticardiolipin units (MPL), and was reported as a weak-positive (a titer of 20-80 UPL) and a strong-positive (a titer of $>80$ UPL).

The presence of total serum anti-ß2GPI antibodies ( $\lg A$, $\lg G$, and $\lg M$ ) was first evaluated using the QUANTA Lite $^{\mathrm{TM}}$ ß2GPI Screen. After this evaluation, reactive sera were tested for the isotype of anti-ß2GPI antibody by specific immunoassays for IgA, IgG and IgM (Quanta Lite $\left.^{\mathrm{TM}}\right)$. These immunoassays were performed as described above for anticardiolipin antibodies, but polystyrene microwell ELISA plates coated with a purified B2GPI were used. The B2GPI antibody level is reported as standard IgA antiß2GPI units (SAU), standard IgG anti-ß2GPI units (SGU), or standard IgM anti-ß2GPI units (SMU). With the excep- 
tion of the qualitative QUANTA Lite ${ }^{\mathrm{TM}}$ B2GPI Screen, a cutoff point of 20 standard units was used in the immunoassays for antiphospholipid antibodies.

Antibody titers are reported as the median and $95 \% \mathrm{Cl}$. The Mann-Whitney test was used to analyze the difference between groups. The Fisher exact test was used to evaluate the association between categorical groups, while the Spearman test was used to identify a correlation between variables. Statistical significance was set at $P<0.05$. Statistical analysis was carried out with GraphPad software.

Twenty-four of 109 (22.0\%) HCV carriers (21 males and 3 females) had IgM anticardiolipin antibodies of moderate titers (titer: $22.5 \mathrm{MPL}, 95 \% \mathrm{Cl}$ : 21.5-25.4 MPL), while three carriers $(2.7 \%)$ were seropositive for IgG anticardiolipin antibodies (titer: 23.0 GPL, 95\% Cl: 20.5-25.5 GPL; Figure 1). There were no $\lg A$ anticardiolipin antibodies in the HCV group. A strong association between IgM anticardiolipin seropositivity and male gender was demonstrated in the individuals infected with $\mathrm{HCV}$ (Fisher exact test, $\mathrm{P}=$ 0.0004).

Twenty-nine of 109 (26.6\%) HCV carriers (15 males and 14 females) had anti-ß2GPI IgA antibodies (titer: 41.0 SAU; 95\%Cl: 52.7-103.9 SAU). IgM anti-ß2GPI antibodies were demonstrated in 20 of 109 (18.3\%, 9 males and 11 females) HCV-infected patients who had a titer of 27.6 SMU (95\%Cl: 23.3-70.3 SMU), while only two (1.8\%) HCV carriers were seropositive for IgG antibodies against this protein (titers, 33.1 and 78.0 SGU). There was no difference between the titers of SAU or SMU of males and females infected with $\mathrm{HCV}(\mathrm{P}>0.05$; Figure 2). Furthermore, anticardiolipin and anti-ß2GPI antibody titers were not correlated $(P>0.05)$.

Except for one healthy individual who was seropositive for $\operatorname{lgM}-a C L$, there were no $\lg A$ or $\lg G$ anticardiolipin or anti-ß2GPI antibodies (cut-off $=20 \mathrm{U}$ ) detected in the healthy individuals of the control group.

In this study, we showed that Brazilian individuals chronically infected with hepatitis $\mathrm{C}$ virus present a significant increase in the production of antiphospholipid antibodies. However, we did not investigate the fine antigen specificity of the antiphospholipid antibodies produced in these individuals. Confirming previous reports, there was no clinical history of antiphospholipid syndrome in their medical records $(12,13)$, nor did documented atypical or infrequent features of this syndrome exist, such as myocardial infarction or intra-abdominal thrombotic events, which are only found in select and elderly populations of HCV carriers (14).

Our findings demonstrated that IgA anti-ß2GPI antibodies are the most prevalent antiphospholipid antibodies in Brazilian HCV carriers. A similar high prevalence of $\lg A$ anti-ß2GPI antibodies was also observed in Brazilian HIV patients from a retrovirus reference center in the same city (15). However, the prevalence of IgM anti-ß2GPI antibodies in HIV patients was low (4.4\%) compared with the

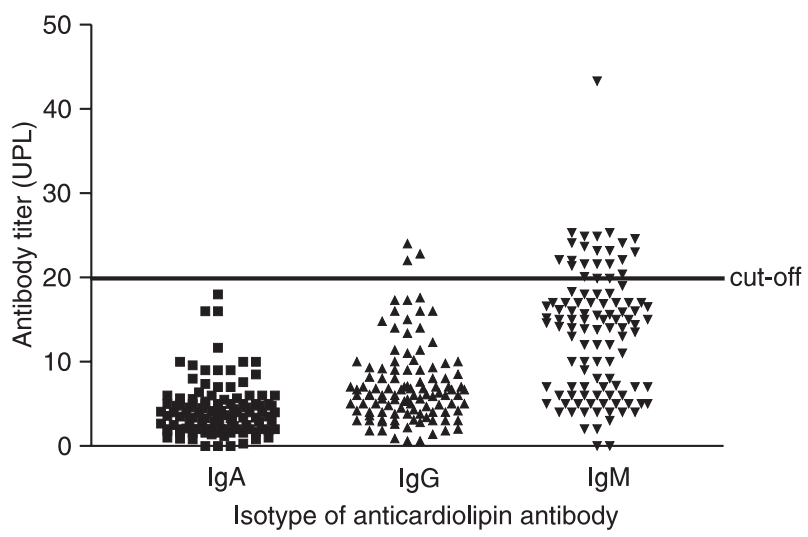

Figure 1. Anticardiolipin antibody levels in hepatitis $C$ virus carriers residing in Salvador, BA, Brazil. The titer of the anticardiolipin antibody isotypes was obtained using QUANTA Lite ${ }^{\mathrm{TM}}$ ELISA for the determination of anticardiolipin antibody-lgA, - $\lg G$, or - $\lg M$ (INOVA Diagnostics, Inc.). The titers of these antibodies in serum samples of $109 \mathrm{HCV}$ carriers are shown in the scattergrams. The horizontal line indicates the cut-off point of $20 \mathrm{UPL}$.

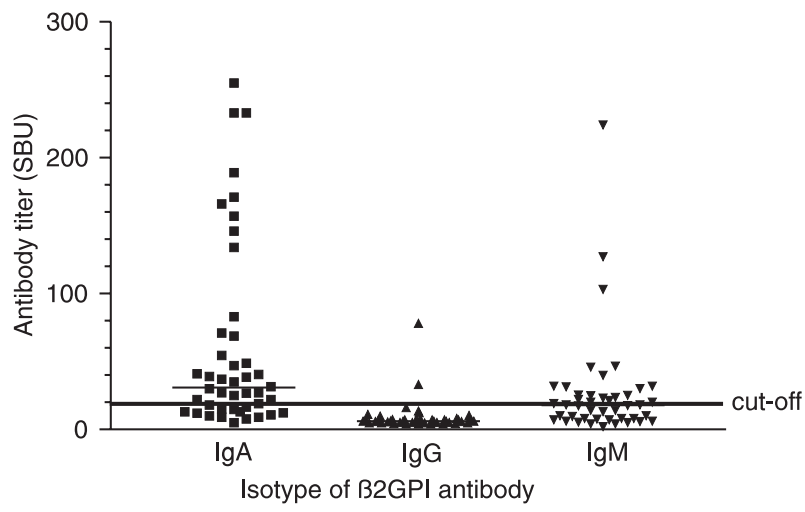

Figure 2. B2-glycoprotein I (B2GPI) antibody levels in hepatitis $C$ virus carriers residing in Salvador, BA, Brazil. The titers of $\lg A$, $\lg$, and $\operatorname{lgM}$ anti-B2GPI antibodies were obtained using QUANTA Lite ${ }^{\text {TM }}$ ELISA GPI-lgA, -lgG, and -lgM, respectively (INOVA Diagnostics, Inc.), and are reported in the scattergrams. Sera from $44 \mathrm{HCV}$ carriers previously classified as seropositive for total antibodies against this protein by the QUANTA Lite ${ }^{T M}$ B2GPI Screen test were evaluated. The median titers of the three isotypes of anti-GPI antibodies are represented by thin horizontal lines. The continuous thick horizontal line indicates the cut-off point of $20 \mathrm{SBU}$. 
prevalence of this antibody (18.3\%) in the HCV carriers investigated in this study (15).

$\lg$ A anti-ß2GPI antibodies have been associated with venous thrombosis, thrombocytopenia, heart valve disease, livedo reticularis, and epilepsy (16). More recently, a strong association between this isotype of anti-ß2GPI antibody and atherosclerosis was demonstrated, thus indicating immune recognition of domain 4 of B2GPI (17). However, the association between coronary artery disease and chronic HCV infection is not conclusive, as indicated by two recent conflicting reports $(18,19)$.

The seropositivity of $\lg \mathrm{A}$ or $\operatorname{IgM}$ anti-ß2GPI antibodies in Brazilian HCV carriers suggests that these immunoglobulins are probably induced by an immune mechanism of molecular mimicry between HCV proteins and B2GPI, in agreement with previous studies (20). Therefore, more studies are necessary to identify the epitopes recognized by $\lg \mathrm{A}$ and $\operatorname{lgM}$ anti-ß2GPI antibodies, and to document coronary artery disease or antiphospholipid syndrome in these HCV carriers. The need to undertake these studies is justified by the finding that antiphospholipid antibodies produced against domains of B2GPI in either viral or bacterial infections are able to induce experimental antiphospholipid syndrome after infusion in mice (20).

\section{References}

1. Pawlotsky JM. Pathophysiology of hepatitis C virus infection and related liver disease. Trends Microbiol 2004; 12: 96-102.

2. Dustin LB, Rice CM. Flying under the radar: the immunobiology of hepatitis C. Annu Rev Immunol 2007; 25: 71-99.

3. Shepard CW, Finelli L, Alter MJ. Global epidemiology of hepatitis C virus infection. Lancet Infect Dis 2005; 5: 558567.

4. Strassburg CP, Vogel A, Manns MP. Autoimmunity and hepatitis C. Autoimmun Rev 2003; 2: 322-331.

5. Sansonno D, Dammacco F. Hepatitis C virus, cryoglobulinaemia, and vasculitis: immune complex relations. Lancet Infect Dis 2005; 5: 227-236.

6. Cacoub P, Renou C, Rosenthal E, Cohen P, Loury I, Loustaud-Ratti $V$, et al. Extrahepatic manifestations associated with hepatitis $C$ virus infection. A prospective multicenter study of 321 patients. The GERMIVIC. Groupe d'Etude et de Recherche en Medecine Interne et Maladies Infectieuses sur le Virus de l'Hepatite C. Medicine 2000; 79: 4756.

7. Muratori P, Muratori L, Stroffolini T, Pappas G, Terlizzi P, Ferrari $R$, et al. Prevalence of non-organ specific autoantibodies in HCV-infected subjects in the general population. Clin Exp Immunol 2003; 131: 118-121.

8. Ramos-Casals M, Font J. Extrahepatic manifestations in patients with chronic hepatitis $\mathrm{C}$ virus infection. Curr Opin Rheumatol 2005; 17: 447-455.

9. McIntyre JA, Wagenknecht DR, Faulk WP. Antiphospholipid antibodies: discovery, definitions, detection and disease. Prog Lipid Res 2003; 42: 176-237.

10. Mangia A, Margaglione M, Cascavilla I, Gentile R, Cappucci G, Facciorusso D, et al. Anticardiolipin antibodies in patients with liver disease. Am J Gastroenterol 1999; 94: 2983-2987.

11. Strader DB, Wright T, Thomas DL, Seeff LB. Diagnosis, management, and treatment of hepatitis C. Hepatology
2004; 39: 1147-1171.

12. Zachou K, Liaskos C, Christodoulou DK, Kardasi M, Papadamou G, Gatselis N, et al. Anti-cardiolipin antibodies in patients with chronic viral hepatitis are independent of beta2-glycoprotein I cofactor or features of antiphospholipid syndrome. Eur J Clin Invest 2003; 33: 161-168.

13. Uthman IW, Gharavi AE. Viral infections and antiphospholipid antibodies. Semin Arthritis Rheum 2002; 31: 256-263.

14. Ramos-Casals M, Cervera R, Lagrutta M, Medina F, GarciaCarrasco M, De La Red G, et al. Clinical features related to antiphospholipid syndrome in patients with chronic viral infections (hepatitis C virus/HIV infection): description of 82 cases. Clin Infect Dis 2004; 38: 1009-1016.

15. Galrao L, Brites C, Atta ML, Atta A, Lima I, Gonzalez F, et al. Antiphospholipid antibodies in HIV-positive patients. Clin Rheumatol 2007; 26: 1825-1830.

16. Lakos G, Kiss E, Regeczy N, Tarjan P, Soltesz P, Zeher M, et al. Isotype distribution and clinical relevance of antibeta2-glycoprotein I (beta2-GPI) antibodies: importance of IgA isotype. Clin Exp Immunol 1999; 117: 574-579.

17. Iverson GM, von Muhlen CA, Staub HL, Lassen AJ, Binder W, Norman GL. Patients with atherosclerotic syndrome, negative in anti-cardiolipin assays, make IgA autoantibodies that preferentially target domain 4 of beta2-GPI. $J$ Autoimmun 2006; 27: 266-271.

18. Vassalle C, Masini S, Bianchi F, Zucchelli GC. Evidence for association between hepatitis $C$ virus seropositivity and coronary artery disease. Heart 2004; 90: 565-566.

19. Momiyama $Y$, Ohmori $R$, Kato $R$, Taniguchi $H$, Nakamura $H$, Ohsuzu F. Lack of any association between persistent hepatitis $\mathrm{B}$ or $\mathrm{C}$ virus infection and coronary artery disease. Atherosclerosis 2005; 181: 211-213.

20. Blank M, Shoenfeld Y. Beta-2-glycoprotein-I, infections, antiphospholipid syndrome and therapeutic considerations. Clin Immunol 2004; 112: 190-199. 